\title{
EUROPEAN UNION AND SUSTAINABLE DEVELOPMENT ASSESSMENT IN THE BUSINESS SECTOR
}

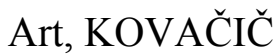 \\ Faculty of Commercial and Business Studies, Lava 7, 3000 Celje, artkovacic@gmail.com, SLOVENIJA
}

\begin{abstract}
Assessment of sustainable position of selected countries is the important challenge in the last years. The sustainable theory has changed from the years of Rio conference and the availability of statistical resources is becoming better. Sustainable development is an important objective for each country. Enlargement of the EU has brought the current priorities and future direction of EU environmental policy sharply into focus. Enlargement process has increased the standards of environmental protection and social development. Significant environmental investments are necessary and the new members need to speed up their preparation for implementing the Goethenburg strategy "sustainable strategy". CEE countries and also SEE countries are implementing sustainable development approach through integration process with European Union. So, the national strategies and development programmes are taking sustainability approach with EU documents
\end{abstract}

KEYWORDS: economic development, benchmarking, development strategy, environmental economics

JEL classification: 01, 024, 038, Q5

UDC: 339,9

\section{INTRODUCTION}

CEE countries and also SEE countries are implementing sustainable development approach through integration process with European Union. So, the national strategies and development programmes are taking sustainability approach with EU documents. Sustainable development has long been on the political agenda of the European Union, with the creation of its Sustainable Development Strategy (EU SDS) and the respective sustainable development indicators (SDI) set. The EU Sustainable development strategies brings together the many strands of economic, social and environmental policy under one overarching objective - to continually improve the quality of life and wellbeing for present and future generations. The Eurostat monitoring report, published every two years, provides an objective, statistical picture of progress towards the goals and objectives of the EU Sustainable development strategies based on the EU Sustainable development indicators set (European Commission, 2016). Sustainable development on business level has to be supported by community. The sustainable development approach has to be implemented on business level. Management in enterprises needs to be responsible to social and environmental goals. In the article will test three hypothesis. First hypothesis is that business progress and environmental protection goes together hand in hand. Second hypothesis is that CEE countries will need to integrate the sustainable development approach in national policies and strategies and also on business level as Corporate social responsibility. Third hypothesis: business sustainability is very accepted in Slovenian enterprises. Corporate social responsibility (CSR) and sustainable development are all new concepts that were mostly unknown through Central Europe less than 20 years ago. Today we can see a growing number of companies in our region that consistently follow in the footsteps of the most advanced global enterprises, implementing strategic initiatives and thus increasing their contribution to sustainable social and economic growth. CSR is regarded as a universal concept based on the triple bottom line principle. But despite this widely acknowledged concept, its interpretation and popularity change over time and differ between regions. This applies not only to world regions such as the U.S. and Europe, but also on smaller scales, e.g. between Western Europe and Central and Eastern Europe (CEE). Europe is the continent that first dealt with the CSR movement. Europe boasts traditionally more consistent CSR values, norms and perceptions compared to other areas of the world. European corporations tend to hold stronger and broader approaches to stakeholder relations, and that network is being established to help companies share and diffuse relevant information about CSR. Through CSR, corporations importantly contribute to the EU's treaty objectives of sustainable development and highly competitive social market economy. While CSR has a particularly strong resonance in parts of Western Europe, it took root slowly in Central and Eastern Europe. As the U.N.Development Program put it: "Due to the socialist heritage, there is a general perception, both in the business community and the public at large, that social responsibility and social caring is the primary role of government. Most companies consider their responsibility to operate in compliance with the legal and regulatory environment of the given country."However, in recent years CSR a became a "hot" 
topic in Central and Eastern Europe. CEE countries are increasingly integrating themselves into the global political and economic system, and there is an emerging need to integrate corporate responsibility in the mainstream management education and executive education. Reputation remains the main focus of CSR in both Western and Eastern Europe. The main drivers for companies to adopt CSR in the CEE region is to protect brands and keep a company's 'licence to operate' — society's approval for their activities. The same is still true for many Western companies, but leaders moved on to addressing how sustainability affects the core business through innovation and strategy. CSR (or sustainability) reporting is taking a similar route. While people in the CEE region are slowly learning how to apply it, in the West most of the companies have already managed to leverage reporting into significant benefits. Committing to CSR reporting led companies to develop their stakeholder relationships and also to improve management communication systems. One of the notable benefits was the setup of public commitments, which assisted companies in moving forward. Now, the new systems have worked into the company culture and yearly reports do not require extra effort. In the CEE region, most of the big players are subsidiaries of multinational corporations normally headquartered elsewhere. Such subsidiaries are applying centrally managed CSR, customized to local laws and regulations. Only some would take the opportunity and make this process a competitive advantage. The other issue is starting a conversation about any type of government intervention; the legacy of communism is vividly remembered. It has to be clear governments should limit the use of sustainability promotion policy measures through market devices not through direct planning. Although, the stance on whether CSR should be regulated or remain voluntary is equally mixed. Corporate social responsibility (CSR) refers to business practices involving initiatives that benefit society. A business's CSR can encompass a wide variety of tactics, from giving away a portion of a company's proceeds to charity, to implementing "greener" business operations. The sustainable development on business level is more important through stakeholder approach. Stakeholder influence strategies should aim at both external pressures (regulations and market changes) and change in internal corporate factors (such as corporate culture) as a basis for affecting corporate environmental strategy and processes. A new strategy on Corporate Social Responsibility ('CSR'), which aims to take forward the contribution of business to sustainable development, was adopted by the European Commission. Corporate social responsibility (CSR) refers to companies taking responsibility for their impact on society. The European Commission believes that CSR is important for the sustainability, competitiveness, and innovation of EU enterprises and the EU economy. It brings benefits for risk management, cost savings, access to capital, customer relationships, and human resource management. The Commission (2016) has defined CSR as the responsibility of enterprises for their impact on society. CSR should be company led. Public authorities can play a supporting role through a smart mix of voluntary policy measures and, where necessary, complementary regulation. Companies can become socially responsible by: following the law; integrating social, environmental, ethical, consumer, and human rights concerns into their business strategy and operations. There are many reasons why is CSR so important. In the interest of enterprises CSR provides important benefits to companies in risk management, cost savings, access to capital, customer relationships, HR management, and their ability to innovate. In the interest of the $\mathbf{E U}$ economy CSR makes companies more sustainable and innovative, which contributes to a more sustainable economy. In the interests of society - CSR offers a set of values on which we can build a more cohesive society and base the transition to a sustainable economic system. The Commission (European Strategy on CSR, 2016) promotes CSR in the EU and encourages enterprises to adhere to international guidelines and principles. Through CSR, enterprises can significantly contribute to the European Union's treaty objectives of sustainable development and a highly competitive social market economy. CSR underpins the objectives of the Europe 2020 strategy for smart, sustainable and inclusive growth, including the $75 \%$ employment target. Responsible business conduct is especially important when private sector operators provide public services. Helping to mitigate the social effects of the current economic crisis, including job losses, is part of the social responsibility of enterprises. CSR offers a set of values on which to build a more cohesive society and on which to base the transition to a sustainable economic system. The sustainable development on business level is more important through stakeholder approach. Stakeholder influence strategies should aim at both external pressures (regulations and market changes) and change in internal corporate factors (such as corporate culture) as a basis for affecting corporate environmental strategy and processes. Alternatives for stakeholder influence include market pressure, sensitive property ownership, legislation/regulation, public policy influence, direct action (often counter-productive in coalitions), lawsuit, mediation/arbitration, dialog/voice and voting representation. Stakeholder theory holds that organizational performance ought to be judged by how effectively managers balance the interests of a multiplicity of external and internal constituents.

\section{IMPORTANCE OF CORPORATE SOCIAL RESPONSIBILITY IN ENTERPRISES}

The corporate social responsibility (CSR) camp focuses on balancing current stakeholder interests. A socially responsible oil company would build local schools and hospitals to compensate communities for their resource extraction. But such measures do not always acknowledge the long-term impact on the communities. Keep in mind that schools and hospitals require staff and ongoing servicing. So CSR measures can actually impose long-term liabilities on affected communities, making good-intentioned actions unsustainable. The common approach to corporate social responsibility is grounded in ethics, morality and norms. And there is no question that many CSR initiatives are good at balancing competing demands made by shareholders and other stakeholders. To do this, however, many supposedly responsible firms borrow resources and capital from the future, which can magnify the imbalance in the distribution of resources between the short and long term. It is time for organizational leaders to stop confusing responsibility with sustainability, which hinders businesses from thinking deeply enough about the inequities created by their actions over time. Simply put, some activities are either responsible or they are sustainable, not both. Charitable donations that relieve social problems are responsible, 
but they are not sustainable if they do not resolve the underlying issue. Corporate Social Responsibility (CSR, also called corporate conscience, corporate citizenship or responsible business) is a form of corporate self regulation integrated into a business model. CSR policy functions as a self-regulatory mechanism whereby a business monitors and ensures its active compliance with the spirit of the law, ethical standards and national or international norms. With some models, a firm's implementation of CSR goes beyond compliance and engages in "actions that appear to further some social good, beyond the interests of the firm and that which is required by law." The binary choice between 'complying' with the law and 'going beyond' the law must be qualified with some nuance. In many areas such as environmental or labor regulations, employers can choose to comply with the law, to go beyond the law, but they can also choose to not comply with the law, such as when they deliberately ignore gender equality or the mandate to hire disabled workers. There must be a recognition that many socalled 'hard' laws are also 'weak' laws, weak in the sense that they are poorly enforced, with no or little control and/or no or few sanctions in case of non-compliance. 'Weak' law must not be confused with Soft law The aim is to increase long-term profits and shareholder trust through positive public relations and high ethical standards to reduce business and legal risk by taking responsibility for corporate actions. CSR strategies encourage the company to make a positive impact on the environment and stakeholders including consumers, employees, investors, communities, and others. Proponents argue that corporations increase long-term profits by operating with a CSR perspective, while critics argue that CSR distracts from businesses' economic role

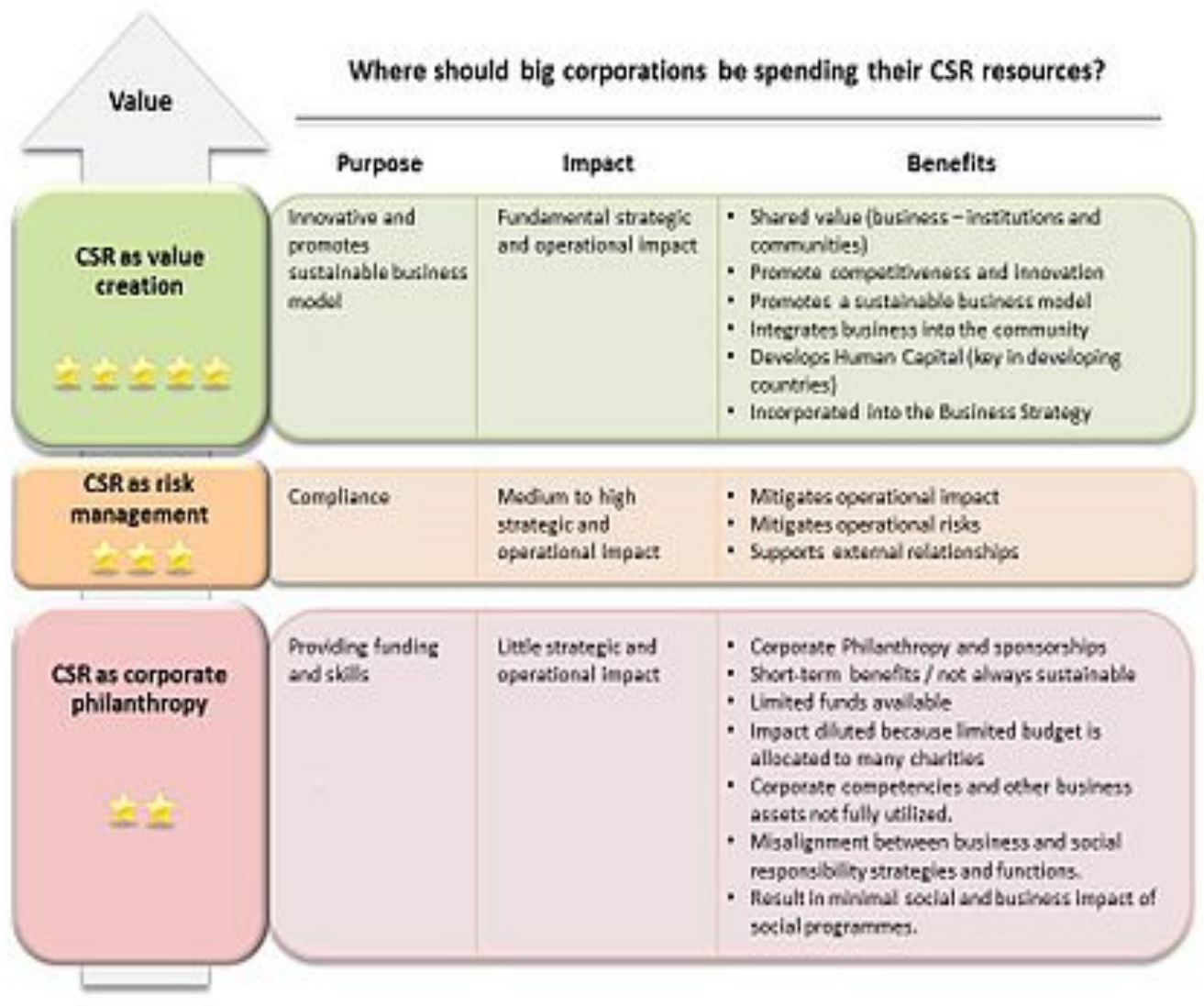

Figure 1. Corporate Social Responibility in enterprise.

Business sector implement the sustainable development also through implementation of corporate social responsibility. This take into account also the sustainable responsibility. The contemporary corporate social responsibility agenda, however, is relatively immature in all countries. Despite widespread rhetoric, its impact is still patchy. In practice, implementation of this agenda by many companies is shallow and fragmented. Governments are beginning to view corporate social responsibility as cost-effective means to enhance sustainable development strategies, and as a component of their national competitiveness strategies to attract foreign direct investment and position their exports in global markets. Company strategy and public policy are alike concerned to match supposed international challenges. This also increasingly affects individuals, who are also required to become competitive in the way they conduct their lives, these demands going under the headings of being flexible, innovative, imaginative entrepreneurial, etc. Companies create external effects through their operations or actions. These effects can be positive for example spills over effects from research and income multiplier effects in local communities - or negative, a classical example being pollution. It is expected that governments or other entities that are external to the market relevant costs if the impact of the externalities is not acceptable to important stakeholders, for example the investment and operational costs of pollution control equipment (Steger, 2004). We are implementing the new european strategy for CSR. A new strategy on Corporate 
Social Responsibility ('CSR'), which aims to take forward the contribution of business to sustainable development, was adopted by the European Commission. The strategy calls for a new social and environmental rôle for business in a global economy and sets up a 'European Multi-Stakeholder Forum' for all players social partners, business networks, civil society, consumers and investors to exchange best practice, to establish principles for codes of conduct and to seek consensus on objective evaluation methods and validation tools such as 'social labels'. CSR is defined as voluntary social and environmental practices of business, linked to their core activities, which go beyond companies existing legal obligations. The strategy will also support CSR in small and medium-size undertakings ('SMEs'), in particular by identifying the business case for CSR and by awareness raising of SMEs. For sustainable assessment is important to take CSR into account. So the management move to sustainable development is the important step. We can't implement the european sustainable strategy without business sector.

\section{BUSINESS SUSTAINABILITY AND COMPETITIVENESS OF ENTERPRISES}

Michael Porter and Mark Kramer propose a fundamentally new way to look at the relationship between business and society that does not treat corporate growth and social welfare as a zero-sum game. They introduce a framework that individual companies can use to identify the social consequences of their actions; to discover opportunities to benefit society and themselves by strengthening the competitive context in which they operate; to determine which CSR initiatives they should address; and to find the most effective ways of doing so. Perceiving social responsibility as an opportunity rather than as damage control or a PR campaign requires dramatically different thinking a mind set, the authors warn, that will become increasingly important to competitive success (Porter, Kramer 2006). IMD asked 1,500 managers in nine industry sectors whether they felt there was a business case for sustainability. The answers they received surprised some people. "Many of our respondents complained about a weak and rather elusive business case due to external stakeholders' significant disinterest or even opposition to corporate sustainability," explains IMD's professor Ulrich Steger. To validate their findings IMD surveyed the stakeholders themselves. After analysing 265 interviews and 370 questionnaires, Steger and his team claim to be able to shed more light on how nine different stakeholders, including financial institutions, governments, communities, unions, NGOs and the media, perceive and influence corporate sustainability. And it seems that things have changed little over the last four years. "Overall, stakeholders exhibit significant disinterest in corporate sustainability," Steger says. "They are primarily concerned about companies' financial performance and competitiveness in today's global markets." This is due to a significant imbalance of power between different groups of stakeholders, explains Steger. "Customers and shareholders are still calling the shots and are generally not exerting much pressure on corporate social and environmental agendas beyond compliance. Given these circumstances, NGOs - as the most demanding stakeholder group - find it difficult to get the necessary buy-in from other stakeholders for their campaigns. The result is largely incremental social and environmental progress in companies." In the light of companies' significant bargaining power, it is not surprising that stakeholders such as governments, communities and unions tend to adopt a collaborative approach to influence them, according to Steger. Many NGOs have also attempted to move beyond their traditional advocacy stance, taking part in stakeholder dialogues and in some cases forming partnerships with the corporate sector. But this approach is highly controversial in the NGO sector and can allow companies to operate in a relative comfort zone surrounding by plenty of carrots but a distinct absence of sticks, Steger says. Many of the stakeholders interviewed for the survey expressed concern over a perceived non-level playing field between firms operating in different parts of the world. Europe, for example, has high social and environmental standards, but this cannot be said of developing countries and emerging economies. One interviewee commented: "It will be interesting to see what is done about China; there is pressure on jobs in Europe. Ultimately, social and environmental criteria may even be used as a trade barrier with quotas and claims of low labour standards and low environmental standards. There is already some noise being made. This is likely to be more significant in the future."But while companies need not worry about increasing pressure right now, things could change. "It would be dangerous to be complacent," says Steger. "After all, one of the few 'iron laws' is that to maintain power, one has to use it responsibly. (Steger 2004)

Governments are beginning to view corporate social responsibility as cost-effective means to enhance sustainable development strategies, and as a component of their national competitiveness strategies to attract foreign direct investment and position their exports in global markets. Company strategy and public policy are alike concerned to match supposed international challenges. This also increasingly affects individuals, who are also required to become competitive in the way they conduct their lives, these demands going under the headings of being flexible, innovative, imaginative entrepreneurial, etc. Companies create external effects through their operations or actions. These effects can be positive - for example spill over effects from research and income multiplier effects in local communities - or negative, a classical example being pollution. It is expected that governments or other entitites that are external to the market relevant costs if the impact of the externalities is not acceptable to important stakeholders, for example the investment and operational costs of pollution control equipment (Steger, 2004). People often use the word sustainability when discussing economic development, environmental stress, and the role of the corporation in society. Definitions of the world vary widely in scope: some are focused tightly on economic and environmental considerations, while others encompass equity, various definitions of justice, and other social criteria. Definitions that are focused enough to be readily 
translated into measurable performance indicators may be thought too narrow to capture all the relevant considerations. Broader definitions, attractive by virtue of their comprehensiveness, may be extremely difficult to translate into measurable indicators and hence into workable policies for governments or businesses. Development process play crucial roles in any process affecting the exploration, utilisation and conservation of natural resources. Hence the need to harness this capacity to meet the projected higher needs for these resources, associated with future development and population growth, as well as their conservation for future generations. Not only that they provide the cutting edge for exploiting known resources, but also provide basis for new knowledge of potentials. As new techniques will result in reduced costs per unit of output, they would also help ensure the sustainability of development and thereby contribute to averting the otherwise ominous prospects of depletion of/or serious degradation of natural resources which, if it occurs, would seriously impair future growth and development. While there are a number of ways that development process could contribute to the effective exploitation of natural resources, priority should be given to areas where efficiency, increased availability and sustainability could be ensured. Environmental, social, institutional and economic developments are strongly linked. They are crucially important for the well being of the current as well as future generations. The term sustainability evokes the image of an economic system able to evolve without deterioration from its current state into the long-term future, being in balance with nature. This balance may be as much psychological as material and energetic (O'Connor 1998). On business level we can see the balance among investors, suppliers, consumers, local community and competitors. Being socially responsible means not only fulfilling legal expectations, but also going beyond compliance and investing more into human capital, the environment and the relations with stakeholders. The experience with investment in environmentally responsible technologies and business practice suggests that going beyond legal compliance can contribute to company's competitiveness. Going beyond basic legal obligations in the social area, for example, training, working conditions, management-employee relations, can also have a direct impact on productivity. It opens a way of managing change and of reconciling social development with improved competitiveness. Effects of corporate sustainability management are of great interest to both companies and society. In particular, its micro level economic effects are often the subject of debates and studies discussing the importance and robustness of a business case for corporate sustainability. Obviously these effects are of major importance to promoters and critics of CSM (corporate sustainability management), so is their qualification (Slazmann et al, 2005). We are implementing the new european strategy for CSR. A new strategy on Corporate Social Responsibility ('CSR'), which aims to take forward the contribution of business to sustainable development, was adopted by the European Commission. The strategy calls for a new social and environmental rôle for business in a global economy and sets up a 'European Multi-Stakeholder Forum' for all players social partners, business networks, civil society, consumers and investors to exchange best practice, to establish principles for codes of conduct and to seek consensus on objective evaluation methods and validation tools such as 'social labels'. The strategy seeks to complement existing initiatives by companies themselves and by public organisations such as the OECD and the UN. CSR is defined as voluntary social and environmental practices of business, linked to their core activities, which go beyond companies' existing legal obligations. The strategy will also support CSR in small and medium-size undertakings ('SMEs'), in particular by identifying the business case for CSR and by awareness raising of SMEs. The Commission has an important role to play in CSR, bringing together businesses across Europe to share best practice and to establish common principles for evaluation. Finally, the Commission will work towards building CSR principles into all other EU policies, for example by promoting better understanding of CSR. We can see the CSR as achieving commercial success in ways that honor ethical values and respect people, communities, and the natural environment. CSR means addressing the legal, ethnical, commercial and other expectations society has for business, and making decissions that fairly balance that claims of all key stakeholders. CSR is viewed as a comprehensive set of policies, practices and programmes that are integrated into business operations, supply, chans, and decision-making processes throughout company, wherever the company does business and includes responsibility for current and past actions as well as future impact. The main function of the enterprise is to create value through producing goods and services that society demands, thereby generating profit for its owners and shareholders as well as welfare and society, particularly through an ongoing process of job creation.

\section{INTERRELATIONS OF BALANCED SCORECARD COMPONENTS WITH ASPECTS OF THE SUSTAINABLE DEVELOPMENT}

The "balanced scorecard" is a strategic planning and management system that is used in business, government and non-profit organizations in order to align business activities to the vision and strategy of the organization, improve internal and external communications, and monitor organization performance against strategic goals. The balanced scorecard has evolved from its early use as a simple performance measurement framework to a full strategic planning and management system. The "new" balanced scorecard transforms an organization's strategic plan from an attractive but passive document into a more stringent system for the organization on a daily basis. It provides a framework that provides performance measurements and helps planners identify what should be done and measured. It enables executives to execute their strategies. In addition to the financial perspective, the balanced scorecard calls for companies to also view performance from three additional perspectives: (1) Learning and growth - how well does an organization learn and innovate?, (2) Internal business process - how well does the organization excel at key processes? and (3) The customer - how well does the organization satisfy the customer? Although the balanced scorecard espouses performance indicators beyond just financial measures, in the private sector financial results remain the ultimate goal (i.e. maximizing shareholder value). Therefore, the financial perspective sits atop the balanced scorecard hierarchy, where the other three perspectives serve as strategic enablers of financial success. "This model does not necessarily work in the public sector. While local governments should be good stewards 
of public funds and remain financially solvent, the ultimate mission of government is different than private companies. Using a version of private sector terminology, the mission of government is to maximize stakeholder value, with stakeholders being taxpayers and other residents within the community. Nine Steps are needed to Success methodology was what the county needed to help with its scorecard development. The first step of the organization's scorecard building process begins with an assessment of the organization's mission and vision, challenges, enablers and values. The first step includes preparing a change management plan for the organization, and conducting a focused communications workshop to identify key messages, media outlets, timing and messengers. In the second step, elements of the organization's strategy, including strategic results, strategic themes, and perspectives, are developed by workshop participants to focus attention on customer needs and the organization's value proposition. In the third step, the strategic elements developed in steps one and two are developed into strategic objectives, which are the basic building blocks of strategy and define the organization's strategic intent. Objectives are first initiated and categorized on the strategic theme level, categorized by perspective, linked by cause and effect (strategy maps) for each strategic theme, and then merged together to produce one set of strategic objectives for the entire organization. In the fourth step, the cause and effect linkages between the enterprise-wide strategic objectives are formalized in an enterprise-wide strategy map. The previously constructed theme strategy maps are merged into an overall enterprise-wide strategy map that shows how the organization creates value for its customers and stakeholders. In the fifth step, performance measures are developed for each of the enterprise-wide strategic objectives. Leading and lagging measures are identified, expected targets and thresholds are established, and baseline benchmarking data is developed. In the sixth step, strategic initiatives are developed that support the strategic objectives. To build accountability throughout the organization, ownership of performance measures and strategic initiatives is assigned to the appropriate staff and documented in data definition tables. In the seventh step, the implementation process begins by applying performance measurement software to get the correct performance information to the correct people at the correct time. Automation adds structure and discipline to the system and helps people make better business decisions. In the eighth step, the enterprise-level scorecard is "cascaded" down into business and support unit scorecards, meaning the organizational level scorecard (the first tier) and is translated into business unit or support unit scorecards (the second tier) and then to team and individual scorecards (the third tier). Cascading translates high-level strategy into lower-level objectives, measures, and operational details and is the key to organization alignment around strategy. In the ninth and final step, an evaluation of the completed scorecard is done. During the evaluation, the organization tries to answer questions such as, are the organization's strategies working? Is the organization measuring the correct things? Has the environment changed? Is money being budgeted strategically?
The Balanced Scorecard is a customer-based planning and process system, which main aim is focusing and driving the change process. Sustainability is also focused on customer needs. That means company needs to implement sustainability into the company's goals. Is there any space in BSC for it? As the sustainability or environmental/green strategy is a nowadays theme of the organization's strategy, it can span the existing balanced scorecard perspectives. The sustainability concept originally refers to how organizations handle non-financial factors related to environmental, social and economic issues. This concept potentially impacts the organizations future. Sustainability includes broader issues in area of ecology, sociology and environment as well as well-being of people and standard of life. In other words it is sustainability seen as "green" practices and can be found throughout the operations of all types of business. The sustainability concept is also synonymous with citizenship reporting, social reporting, triple-bottom-line reporting, and other terms that encompass the economic, environmental, and social aspects of an organization's performance and planning. Balanced Scorecard is a multidimensional system meant for identification, implementation and management of strategy on all the organizational levels while focussing company's goals, initiatives and measurements on it. This is the technique that allows organization to translate its vision into a consistent, directional set of performance means and quantitative indices, that not only indicates results but also points to indices that have effect on results achieved. Precise identification of predicted results and means for implementation, that directly influence results achievement, i.e., causative relation, enables managers to concentrate and evoke abilities and knowledge of different organizational components for the achievement of long-term goals. BSC offers a general picture of organization's operation by integrating financial measures with the other performance indicators through perspectives of customers, processes and development. It is very important to select an appropriate system of measures and means that allows to identify vision as a specific strategy that might in turn be translated in a language of quantitative indices, precisely reflecting direction of organization's development and Integration of Sustainable Development Principles into the Balanced Scorecard 465 appropriately evaluating changes. In many cases, systems for organization management and control are based on financial indices and tasks that are not closely associated with the progress made by organization in pursuit of its long-term strategic goals. Focus on short-term financial goals leaves a gap between the strategy development and its implementation. BSC integrates traditional financial goals with the criteria that are meant to measure performance from different points of view. It enables organization to pursue its financial targets relevant for its investors while at the same time controlling progress of capacities and non-material resources beneficial for its future growth. In accordance with this system, managers do not use short-term financial measures as indicators of company performance. System allows offering them four new processes of strategy management that - in combination and individually-enable to match longterm strategy with the short-term factors. 


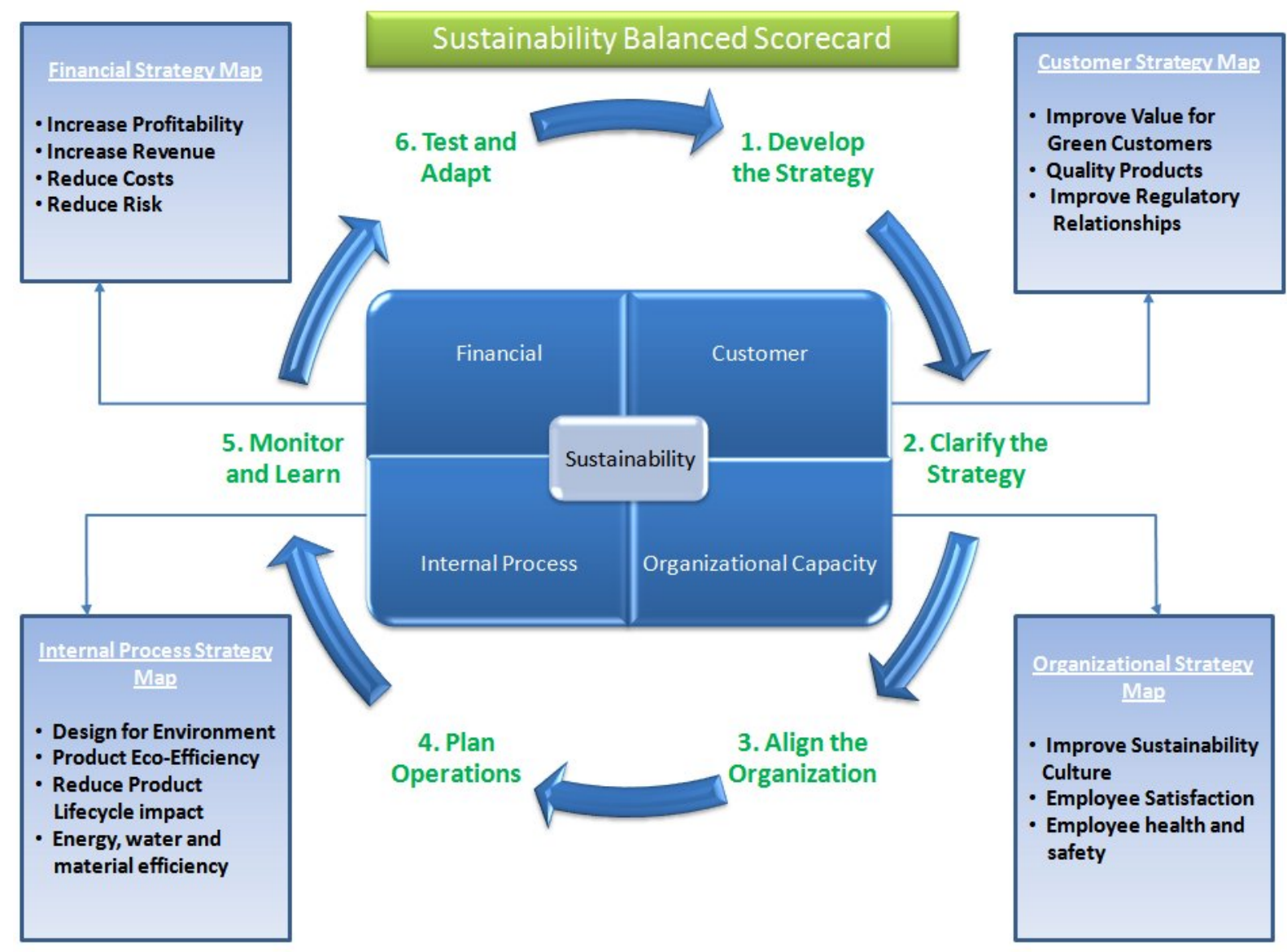

Figure 2. Sustainability Balanced Scorecard

Balanced scorecard of sustainable development assist in implementing soft factors such as environmental and social goals into the general strategy of the organization instead of implementing them as secondary systems. Concept of Balanced Scorecard of Sustainable Development (hereinafter-BSCSD) is very young and in its evolution phase yet, consequently scientific literature reveals different attempts by authors to create and develop BSCSD models that are accordingly interpreted and evaluated in peculiar ways. However, given the increasing variety of such models, there is a lack for the single integrating approach that could assess all the models in a common context. It is the case in literature, that a particular single model is emphasized by accentuating its benefits for organizations, however no attention is dedicated to their advantages and disadvantages in light of their comparison. Research in different sectors (construction and building, food, chemistry, IT, goods transportation, machinery manufacture), with regard to aspects of competitive environment management, shows that strategies of sustainable development can be classified by their strategic orientation (market or society) and strategic behaviour (reactive or proactive) (Dyllick 1999; Gminder, Bieker 2002). Authors present the following 5 strategies how organization can behave while implementing principles of sustainable development in its operation:

- Safe strategy aims at risk management and minimization;

- Strategies of the Credible type deal with image and reputation issues;

- Efficient strategies make improvement of productivity and efficiency possible;
- Innovative strategy is aimed at differentiation of organization's products and services in the market;

- Transformative strategies are used to create new markets by effecting both social and public structures.

Each type of sustainability strategy shows a different level of involvement of environmental and social management into operation of organization and different level of attention dedicated to stakeholders

\section{BUSSINESS SUSTAINABILITY IN ENTERPRISES}

In business research we have measured the sustainable development in Slovenia. I have daveloped an own questionnaire for measuring sustainability level in enterprises. With the collaboration with the IMD Laussanne I have reseived some instructions about creation a questionnare. Questionnare measure the determinants of environmental regulation, sustaianable management in enterprises, business functions in enterprises, characteristics of sustainable development, incentives of sustainable development in enterprises, enterprises orientation towards sustainability, and barriers toward sustainable development in enterprises. So the sustainability evaluation is a business research. 1000 slovenian enterprises were involved in the research. Big, medium and small enterprises have an important part. Management in slovenian enterprises have done $n$ sustainability evaluation. Scale on the survey is from 1 to 6 . In the tables can be seen which indicator have the best position. 


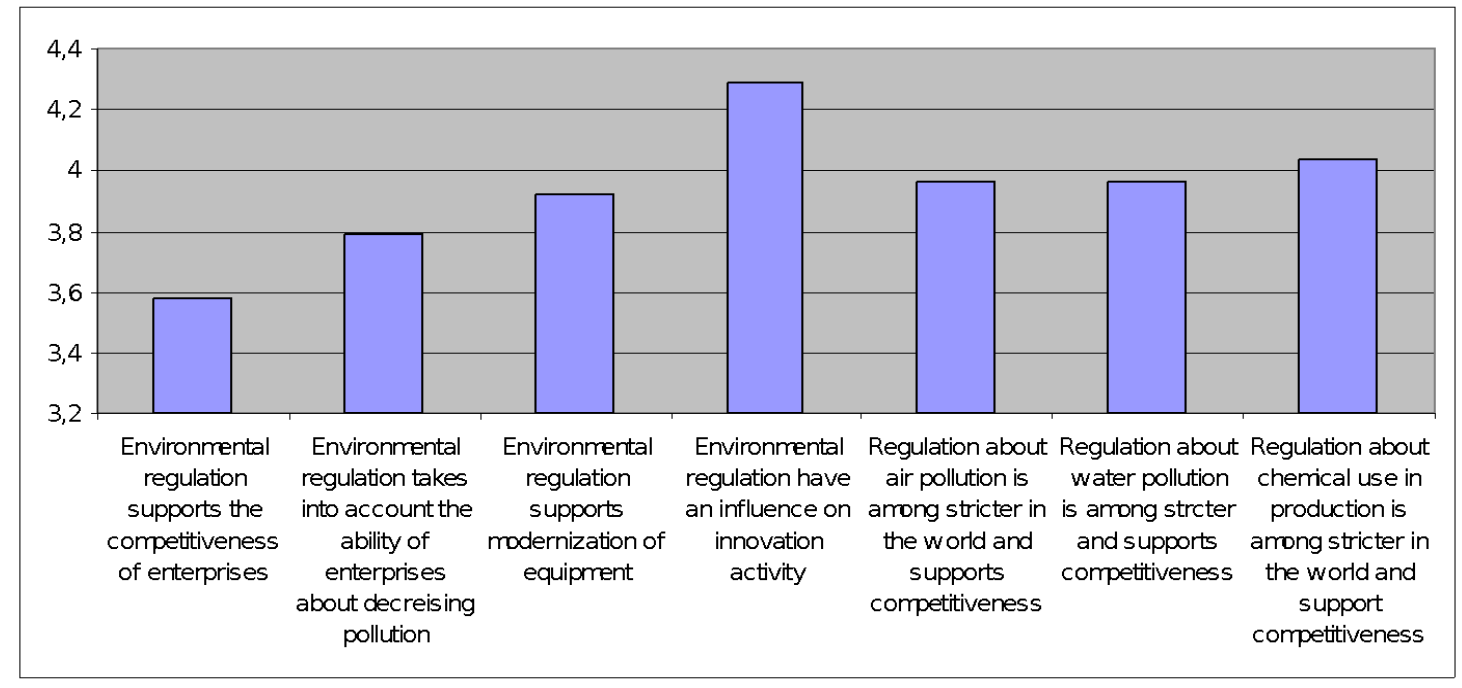

Source: own survey

Environmental regulation is measured by some questions: Does environmental regulation supports the competitiveness of enterprises. Environmental regulation has to support the green investments in the country. The next qustion is does environmental regulation takes into account the ability of enterprises about decreising polution. European internal market is sometimes to strick about this instrument. The thirt indicator of envuironmental regulation ask If environmental regulation supports modernisation of equipment. The important thing is that companies need to by the more eco frendlly equipment. The next question is does environmental regulation has an influence on innovation activity. The fifth question is does environmental regulation about air pollution is stricker in the world and support competitiveness. We don't want that environmental regulation kill the companies. The sixth question ask is the regulation about water pollution stricke in the world and support competitiveness. The last question ask is the regulation about chemical use and production among stricker in the world and support competitiveness. Chemical industry is important part od each industry. We want that chemical industry became competitive. Characteristics of environmental regulation in Slovenia are: Environmental regulation have a strong impact on innovation activity $(4,29)$. Questionnaire answers of managers have shown that position in enterprises. Problem is, that Slovenian environmental regulation don't support the competitiveness action in enterprises $(3,58)$.

\section{Figure 4. Graph 2: SUSTAINABLE MANAGEMENT IN ENTERPRISES}

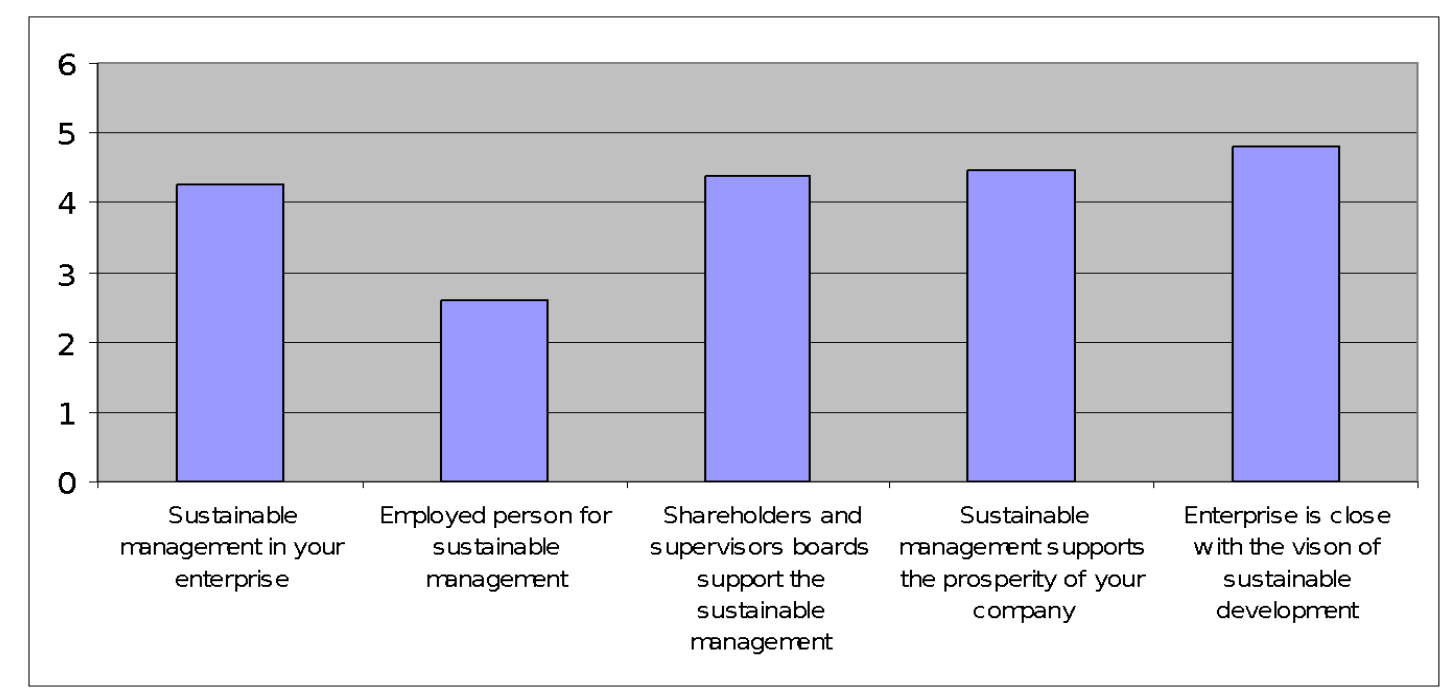

Source: own survey

Management in enterprises have to be sustainability oriented. First question is does exist the sustainable management in enterprises. The second question is does company have employed person for sustainable management. The third question is does shareholders and supervisors boards support the sustainable management, The fourth question is does sustainable management supports the prosperity of the company. We want that the company is competitive on european internal market. The 
last question ask is the enterprise close with the vision of sustainable development. Enterprises in Slovenia have implemented the concept of sustainable development. Sustainable management increase the prosperity in slovenian enterprises. Problem can be seen that enterprises don't have an employed person for sustainable management.

\section{Figure 5. Graph 3: BUSINESS FUNCTIONS IN ENTERPRISES}

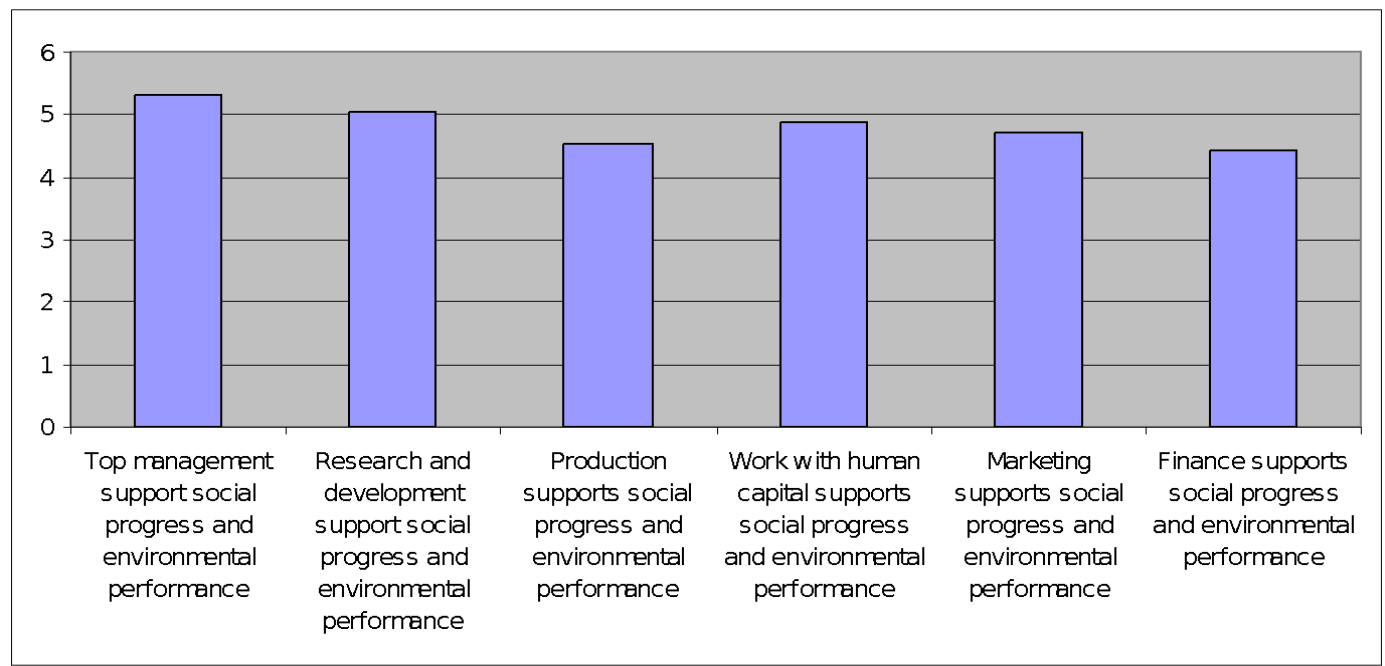

Source: own survey

Business functions in enterprises need to support the sustainable development. It ias not just the management of the company but all devisons in company. First question is does top management support social progress and environmental performance. We would like to know something about sustainable responsibility of the directors. Second indicator ask does research and development supports social progress and environmental performance. We need more eco innovations in enterprises. The third question is does production supports social progress and environmental performance. Production is always the most problematic thing from the view of sustainability. The fourth question ask does work with human capital supports social progress and environmental performance. Aditional training and

Figure 6. Graph 4: CHARACTERISTICS OF SUSTAINABLE DEVELOPMENT IN ENTERPRISES

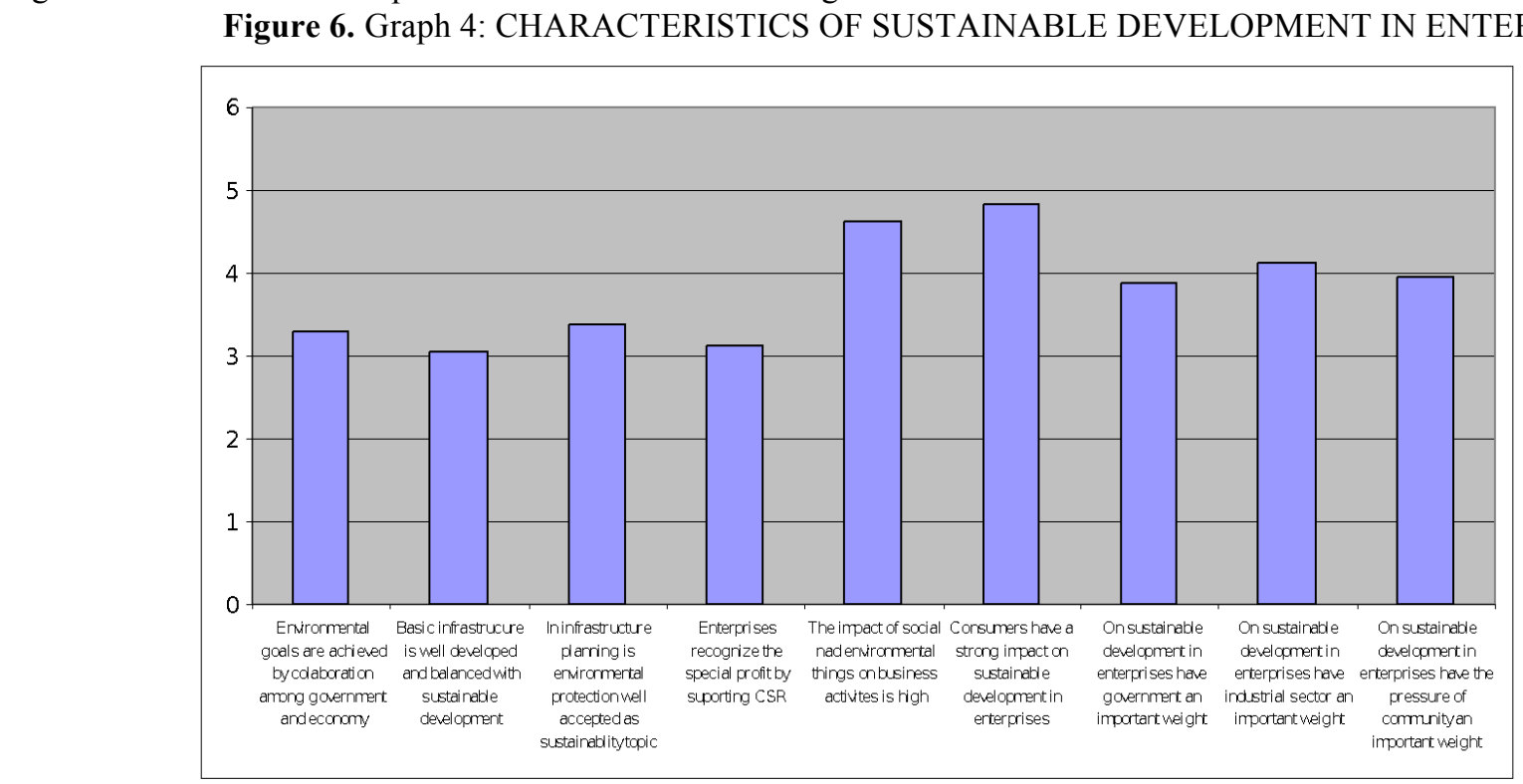

Source: own survey

education programmes need to implement the sustainability approach. The fifith question is does marketing supports social progress and environmental performance. The last question is does finance supports social progress and environmental performance. The financial sector has to implement the sustainable development approach. Orientation of the business function in enterprises about social progress and environmental performance is seen in the graph. Top management supports the social progress and environmental performance $(5,33)$. Business function finance has the lowest impact on social progress and environmental performance $(4,42)$. 
Characteristics of sustainable development in enterprises are important if we would like to understand the modern business sector. First question ask are the environmental goals achieved by collaboration among government and economy, We would like to have strong support toward environmental goals on institutional and business level. The second question is does is basic infrastructure well developed and balanced with sustainable development. We would like to have sustainable infrastructure. The third question is about infrastructure planning in the line with environmental protection. The fourth question is does enterprises recognize the special profit by supporting Corporate social responsibility. More green european internal market have to support companies with CSR orientation. The fifth question is about impact of social and environmental things on business activity. The impact need to be high. The sixth question is does have consumer on sustainable development in enterprises. Consumer have to dictate the progress towards sustainable development. The seventh question is does government has an important weight in supporting sustainable development in enterprises. The eight question is does have the whole industrial sector important weight on sustainable development implementation. The ninght question is does community have in important weight on implementation of sustainable development. By charateristics of sustainable development in enterprises can be seen that consumers have a strong influence on sustainability orientation of enterprises. Enterprises on the other side don't see a special profit by implementation of CSR (Corporate social responsibility). Management have a low opinion about wide consens by achiving environmental and social goals.

Figure 7. Graph 5: INCENTIVES OF SUSTAINABLE DEVELOPMENT BY ENTERPRISES

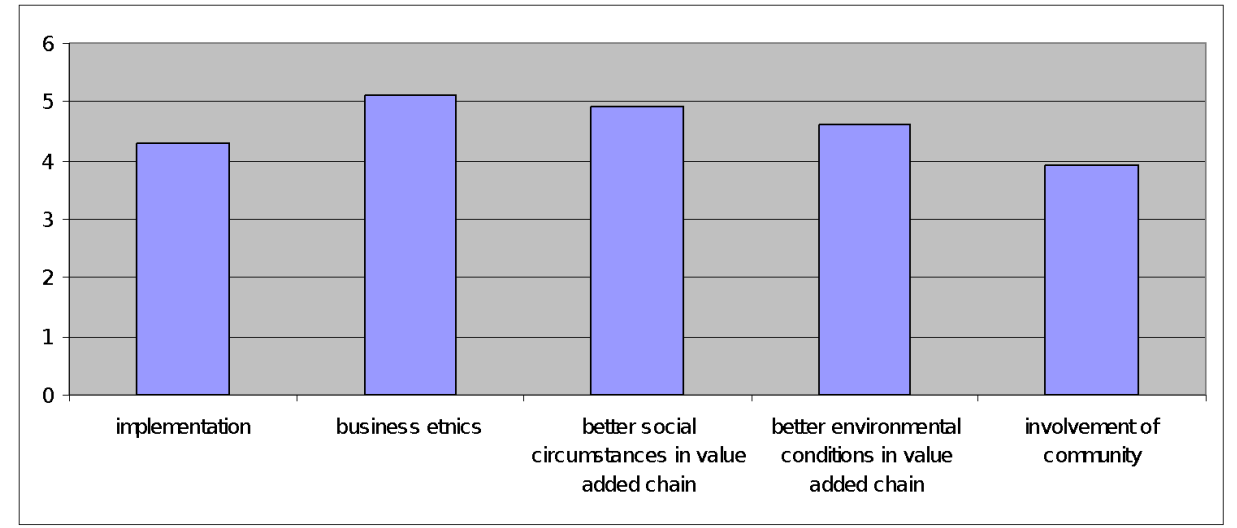

Source: own survey

Incentives of sustainable development by enterprises are measured by five indicators. The first question is about implementation of sustainable development. It is not enough if we have sustainable development programmes and strategies written on the paper. The real imlpemantation has to be done on all level in divisions of enterprises. Business etnics is the second indicator about incentives. The thirth question is about better social circumstances in value added chain. The fifth question is about better environmental conditions in value added chain. The last questions is about involvement of community. In the was that community has an influence on enterprises we can expect better business sustainability. Among incentives of sustainable development in enterprises have better social conditions in the whole chain value a special weight. Better business etnics is an important incentive of sustainable development on entrepreneurship level. On the other side harder involvement of community doesn't bring an important incentive for sustainable development.

Figure 8. Graph 6: ENTERPRISES ORIENTATION TOWARDS SUSTAINABILITY

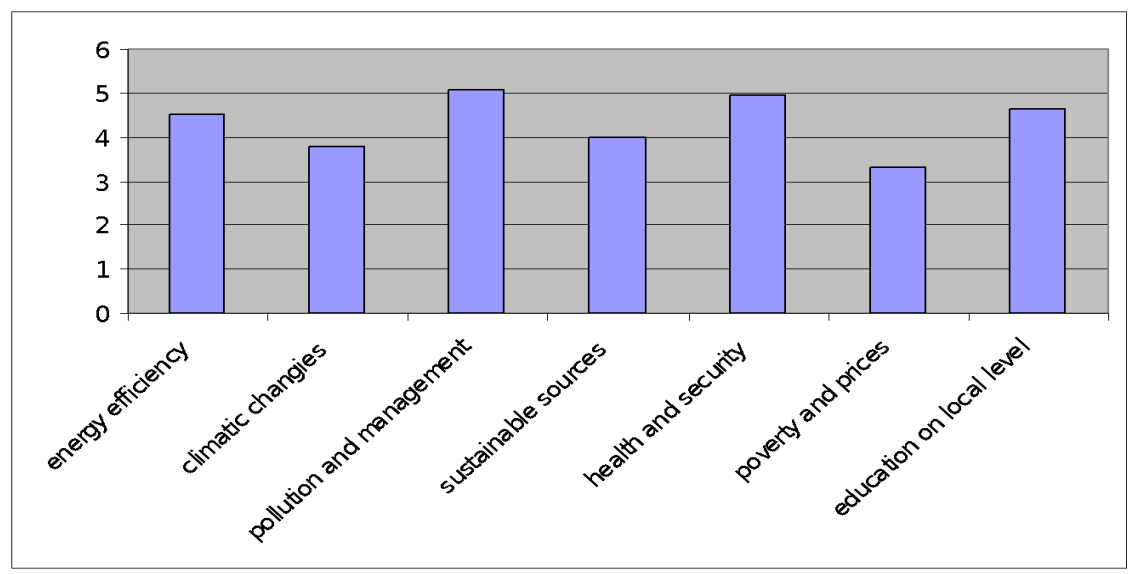

Source: own survey 
Enterprises orientation toward sustainability is measured seven indicators. First indicator show the energy efficiency in enterprises. The second indicators is about climatic changies. The third indicator show connection among pollution and management. The fourth indicator show the sustainable sources. The fifth indicator show the health and security. The sixth indicator shows the poverty and prices. The last indicator show the education on local level. Educational programmes have to implement the sustainable development. Slovenian enterprises give a special attention to pollution, health and security. On the other side can be seen a low interest to poverty and prices.

Figure 9. Graph 7: BARRIERS TOWARDS SUSTAINABLE MANAGEMENT

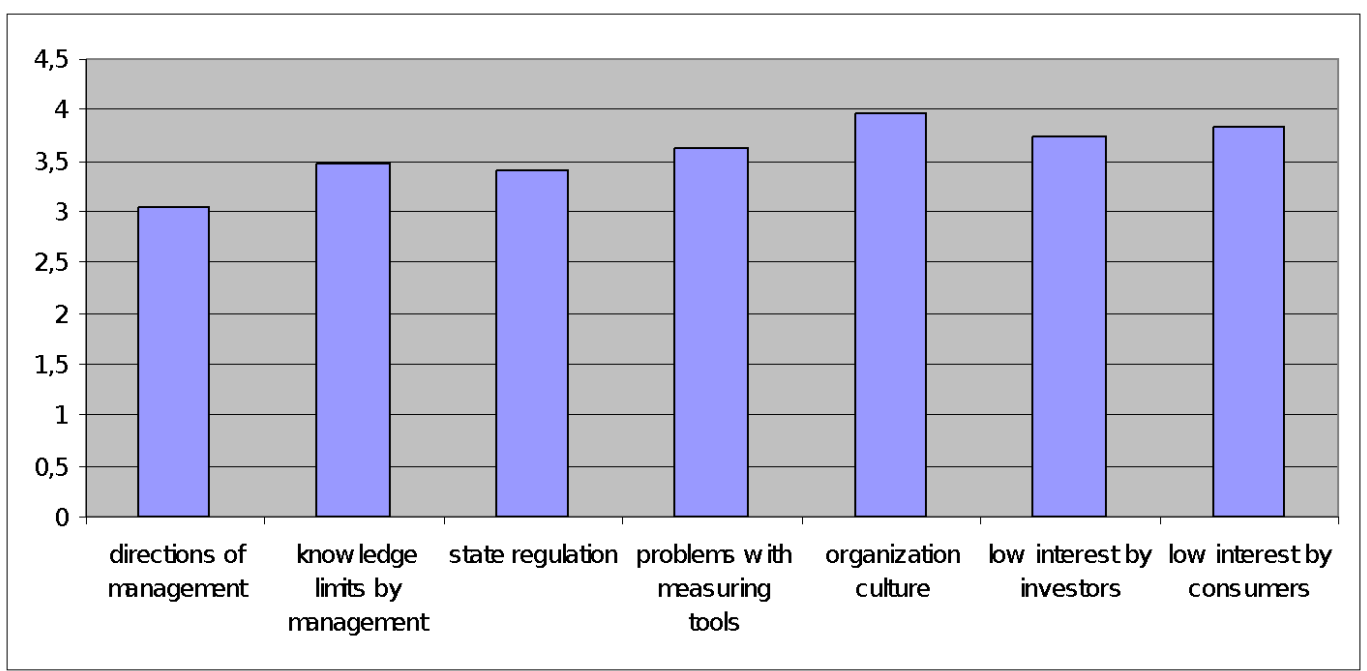

Source: own survey

Barriers towars sustainable management are measured by seven indicators. First indicators shows the direction of management. In the way that directors don't support sustainability we have many problems. The second barrier is knowledge limits by management. The third barrier is state regulation, State regulation have to be modern and support sustainable development. The fourth indicators is problems with measuring tools. Enterprises need to have sustainability balanced scorecard. The fifth indicator is organisation culture. The sixth indicator is low interest by investors. The last indicator is low interest by consumers. The biggest barriers toward sustainable management are organisation culture, and low interest by consumers. On the other side is a low barrier a directions of management. The state regulation is also a low barrier toward sustainable management.

\section{CONCLUSION}

The EU Sustainable development strategies brings together the many strands of economic, social and environmental policy under one overarching objective - to continually improve the quality of life and well-being for present and future generations. The Eurostat monitoring report, published every two years, provides an objective, statistical picture of progress towards the goals and objectives of the EU Sustainable development strategies based on the EU Sustainable development indicators set. All hypothesis in the article stands. In business research we have measured the business sustainability. I have daveloped an own questionnaire for measuring sustainability level in enterprises. With the collaboration with the IMD Lausanne I have reseived some instructions about creation a questionnare. Questionare meassure the determinants of environmental regulation, sustainable management in enterprises, business functions in enterprises, characteristics of sustainable development, incentives of sustainable development in enterprises, enterprises orientation towards sustainability, and barriers toward sustainable development in enterprises. So the sustainability evaluation is a business research. 1000 slovenian enterprises were involved in the research. Big, medium and small enterprises have an important part. Management in slovenian enterprises have done a sustainability evaluation. Characteristics of environmental regulation in Slovenia are: Environmental regulation have a strong impact on innovation activity $(4,29)$. Questionnaire answers of managers have shown that position in enterprises. Problem is, that Slovenian environmental regulation don't support the competitiveness action in enterprises $(3,58)$. Enterprises in Slovenia have implemented the concept of sustainable development. Sustainable management increase the prosperity in slovenian enterprises. Problem can be seen that enterprises don't have an employed person for sustainable management. Top management supports the social progress and environmental performance $(5,33)$. Business function finance has the lowest impact on social progress and environmental performance $(4,42)$. By charatheristics of sustainable development in enterprises can be seen that consumers have a strong influence on sustainability orientation of enterprises. Enterprises on the other side don't see a special profit by implementation of CSR (Corporate social responsibility). Management have a low opinion about wide consens by achiving environmental and social goals. Among incentives of sustainable development in enterprises have better social conditions in the whole chain value a special weight. Better business etnics is an important incentive of sustainable development on entrepreneurship level. On the other side harder involvement of community doesn't bring an important incentive for sustainable development. Educational programmes have to implement the sustainable development. Slovenian enterprises 
give a special attention to pollution, health and security. On the other side can be seen a low interest to poverty and prices. The biggest barriers toward sustainable management are organisation culture, and low interest by consumers. On the other side is a low barrier a directions of management. The state regulation is also a low barrier toward sustainable management. Business sustainability is well developed in Slovenian companies. European single market support the more ecological and social orientation of enterprises.

\section{REFERENCES}

1. Dahl, A.L. (2005) The Competitive Edge in Environmental Responsibility, in The Global Competitiveness Report 20042005, WEF Geneve

2. Dyllick, T. (1999) Environment and Competitiveness of Companies, International management benchmarks

3. EBRD (2002) Transition, welfare and sustainable development, in Transition report 2002, pp 3-13

4. ESI report, 2005, 2005 Environmental Sustainability Index, Yale University

5. EPI report 2006, Pilot 2006 Environmental Performance Index, Yale University

6. Esty, D. (2001) Digital Earth: Saving the Environment, OECD Observer (May 2001) OECD Paris

7. Esty, D. (2002) Why Measurement matters, Environmental Performance Measurement 2001-2002, IMD Lausanne

8. Esty, D., Porter, M. (1998) Industrial Ecology and Competitiveness, Journal of Industrial Ecology Vol 2, No. 1 (winter 1998)

9. Esty, D., Porter, M. (2002) National Environmental Performance Measurement and Determinants, Environmental Performance Measurement 2001-2002, IMD Lausanne

10. European Commission, (2016) Sustainable development in the European Union, Sustainable development indicators, Brussels

11. European Commission (2016) European strategy on Corporate Social responsibility, Brussels

12. Faucheux S, Nicholai I (1998). Environmental Technological Change and governance in Sustainable Development Policy, Ecol. Econ. 3(27):243-256 Fischer K, Scot J (1993). Journal of Environmental Economics and Management, 2(37):165182

13. Gminden, C.U. Bieker, T. (2002) Managing CSR by using the Sustaianble Balanced Scorecard, International Conference of the Greening of the Industry Network
14. Indicators of SD for UK (1996) Department of the Environment: London

15. Levy, M. (2002) Measuring nation's Environmental Sustainability, Environmental Performance Measurement 2001-2002, IMD Lausanne

16. Levy, M., Maier, P. (2004) Early Warning and Assessment of Environment, Conflict and Cooperation, UNEP and Woodrow Wilson Center

17. Mullerat, R (2013) Corporate Social Responsibility: A European Perspective Ramon Mullerat

18. The Jean Monnet/Robert Schuman Paper Series Vol. 13 No.6 June 2013

19. O'Connor, M. (1997) "Environmental Valuation from the Point of view of Sustainability" in Dragun, A.K., Jacobbson, K.: Sustainability and Global Environmental Policy, Edward Elgar: Cheltenham, pp 149-80

20. OECD, (2002) Overview of Sustainable Development indicators used by national and international agencies, OECD Statistical working paper 2002/1, OECD Paris

21. Owens, S., Cowell, R. (1994) Land and Limits, Interpreting sustainability in the planning process, Routledge, London

22. Porter, M., van der Linde, C. (1995); Toward a new Conception of Environmental Competitiveness Relationship, Journal of Economic Perspectives Vol. 9. No. 4 (fall 1995)

23. Porter, M.K., Kramer, M.R. (2006) Strategy and Society: The Link Between Competitive Advantage and Corporate Social Responsibility, Harward Business Review, ( DECEMBER 2006 ISSUE), pp 78-92

24. Pyle in Forrant, (2002) Globalization, Universities and issues of Sustainable Human Development, Edward Elgar Cheltenham

25. Reinhardt, F. (2003) Tests for Sustainability, in The Global Competitiveness Report 2002-2003, WEF Geneve, pp 355366

26. Walley, N., Whitehead, B. (1994) It is Not Easy Being Green, Harvard Business Review Vol 72, No 11-12 (MayJune 1994) pp 46-52

27. Salzmann, O., Ionescu-Somers, A., Steger, U. (2005) The Business Case for Corporate Sustainability: Literature Review and Research Options, European Management Journal Vol. 23, No. 1, pp. 27-36

28. Steger, U. (2004) The Business of Sustainability, Palgrave MacMillan, New York. World Academy of Science, Engineering and Technology pp 30-42 